\title{
Global characteristics of auroral Hall currents derived from the Swarm con- stellation: dependences on season and IMF orientation
}

Tao Huang et al.

Correspondence to: Tao Huang (terence@whu.edu.cn)

The copyright of individual parts of the supplement might differ from the CC BY 3.0 License. 


\section{Supplements}
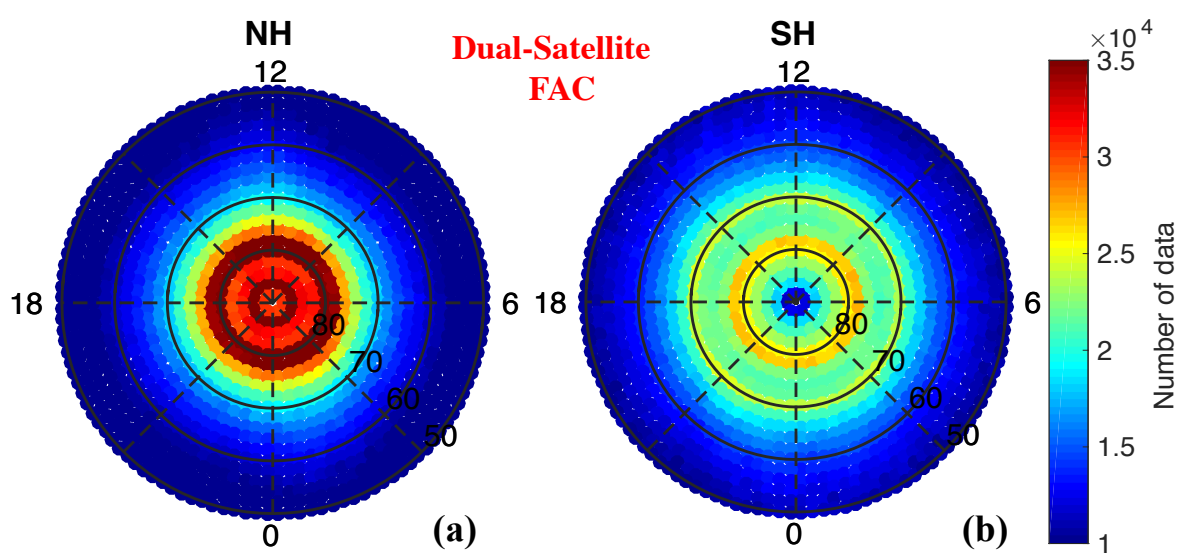

3 Figure SC1. The dual-satellite FAC data coverage from April 2014 to April 2017. The 4 left (right) panels represent the Northern (Southern) Hemisphere. The color indicates 5 the number of samples in each bin.
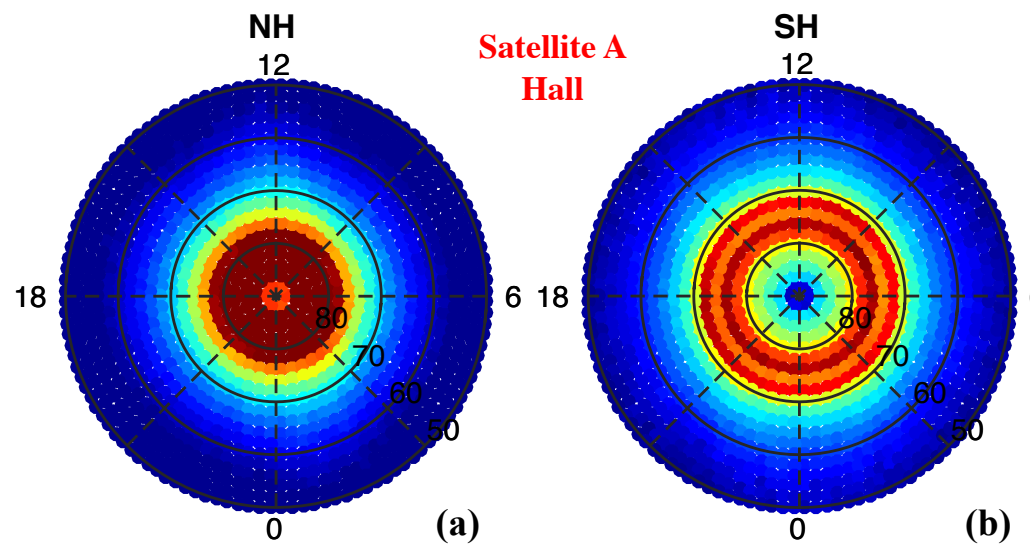

(b)

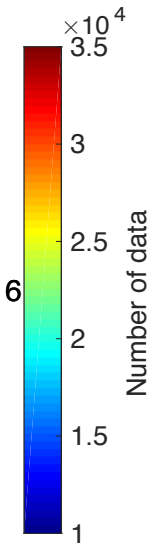

Figure SC2. Same format as Figure SC1 but for the Hall current derived from Satellite A. 
PC: 10-14 MLT
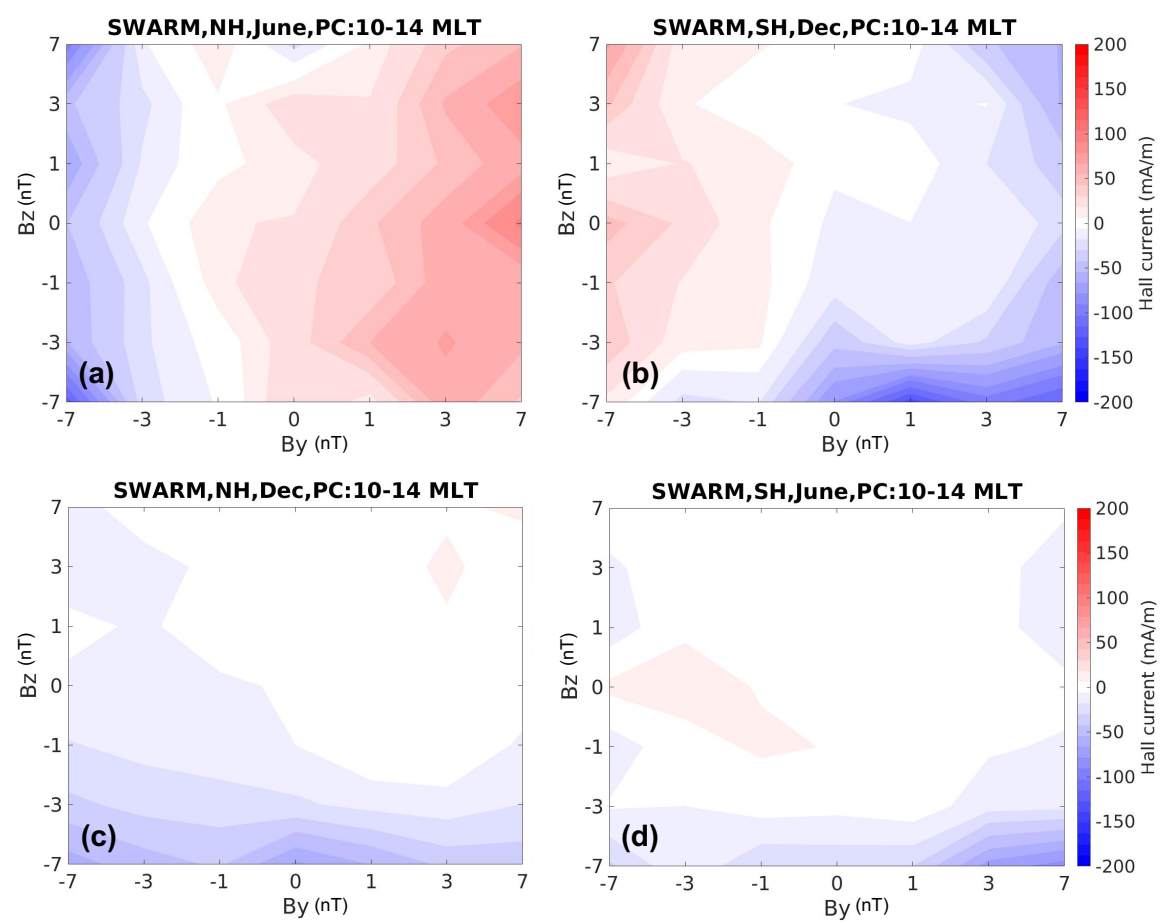

Figure S1. IMF dependence of Hall current in the polar cap around noon sector (10-14 11 MLT).

\section{PC: 22-02 MLT}
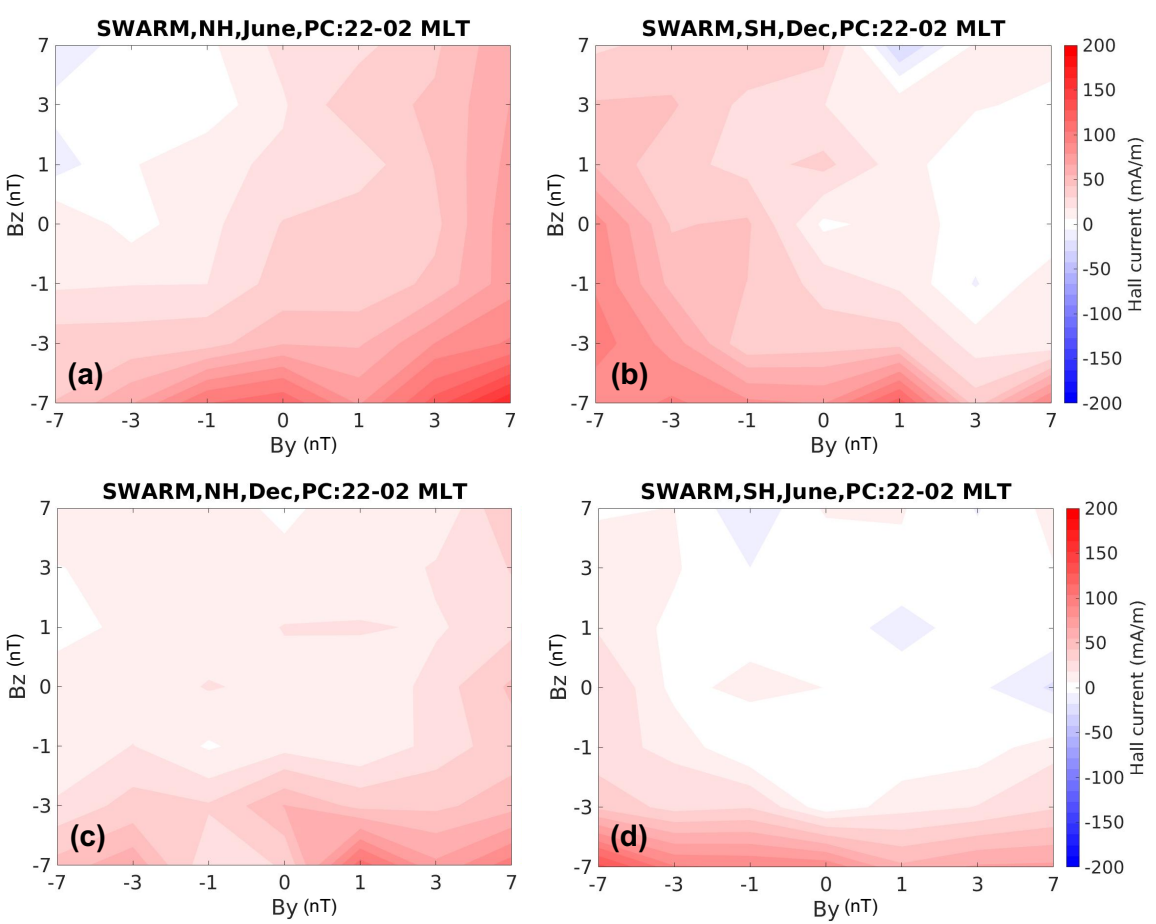

13 Figure S2. Same format as Figure S1 but for the midnight polar cap. 
AZ: 10-14 MLT
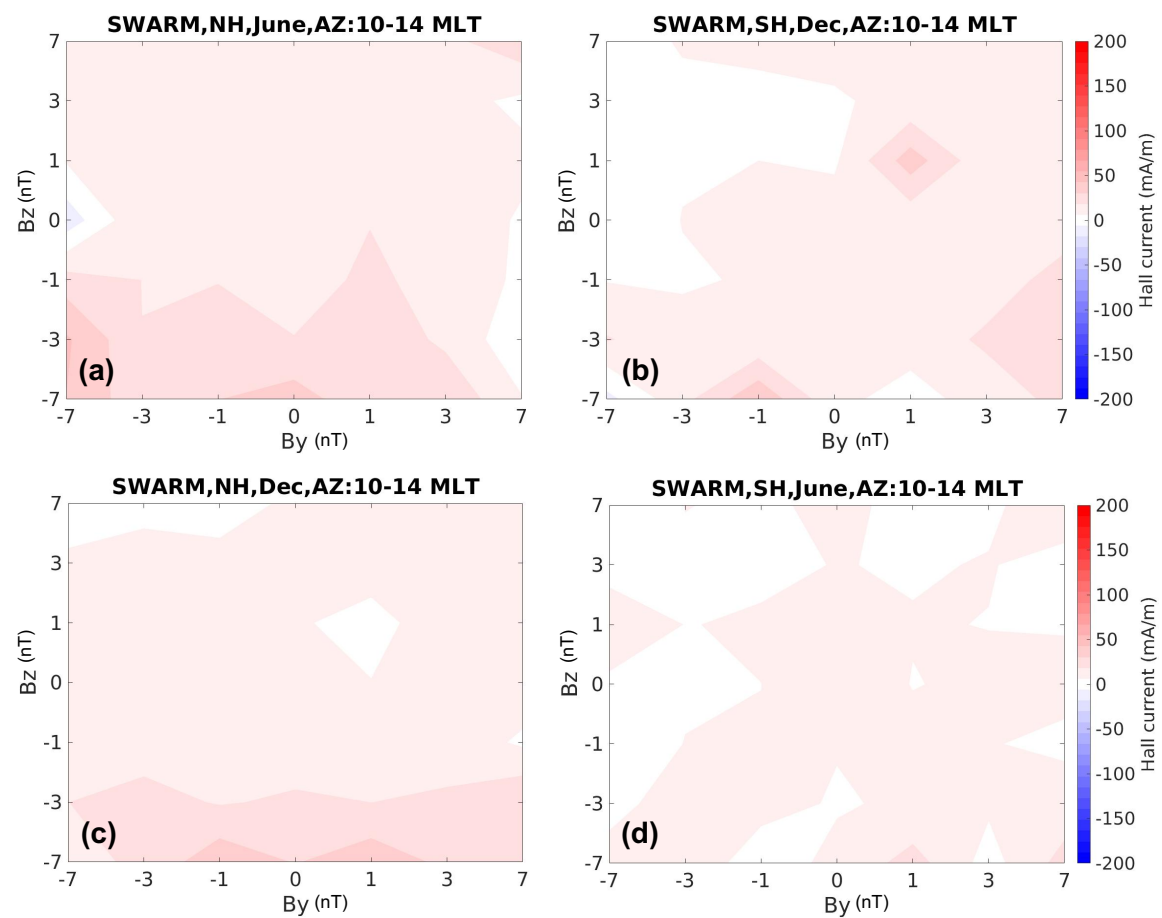

Figure S3. Same format as Figure S1 but for the noon sector at auroral/ subauroral 16 latitudes.

\section{AZ: 22-02 MLT}
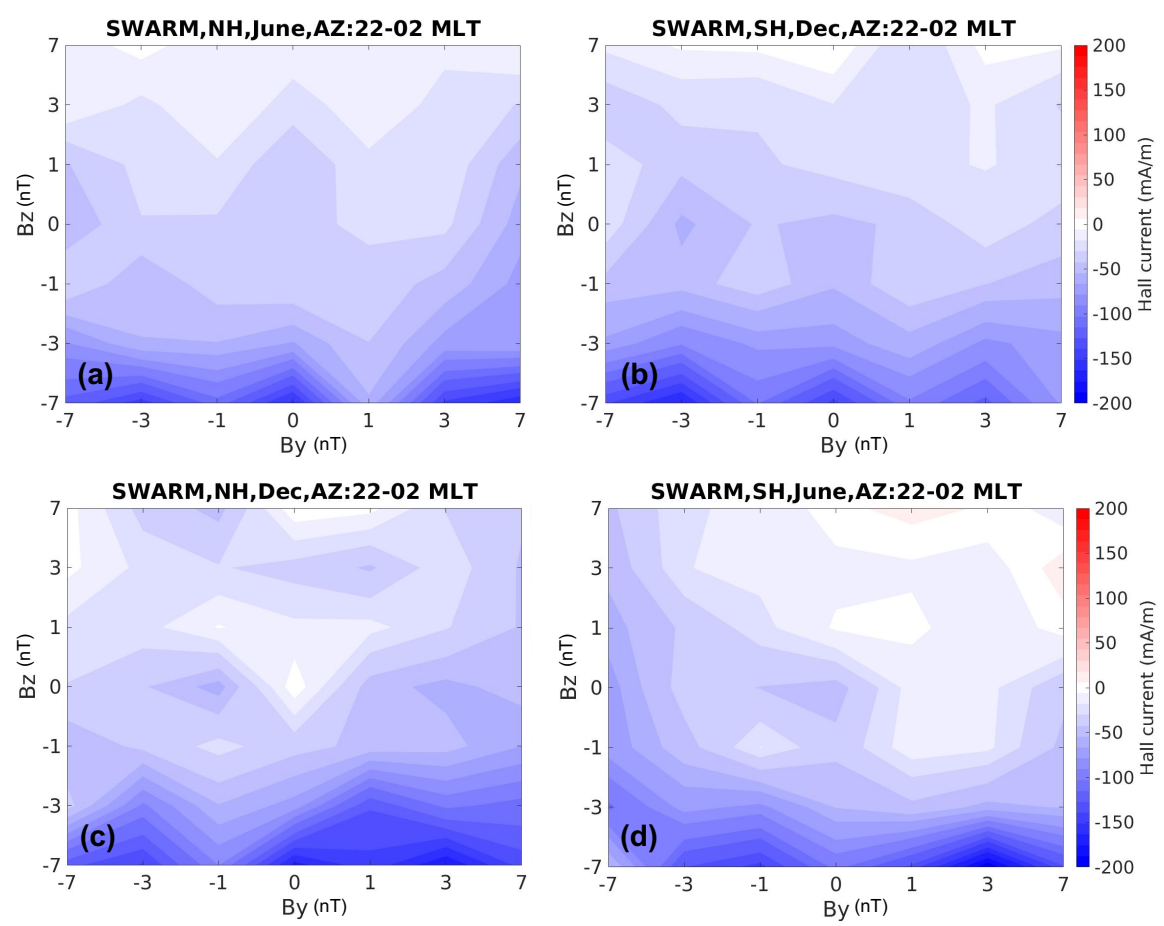

18 Figure S4. Same format as Figure S1 but for the midnightside sector at auroral/ 19 subauroral latitudes. 
PC: 02-10 MLT
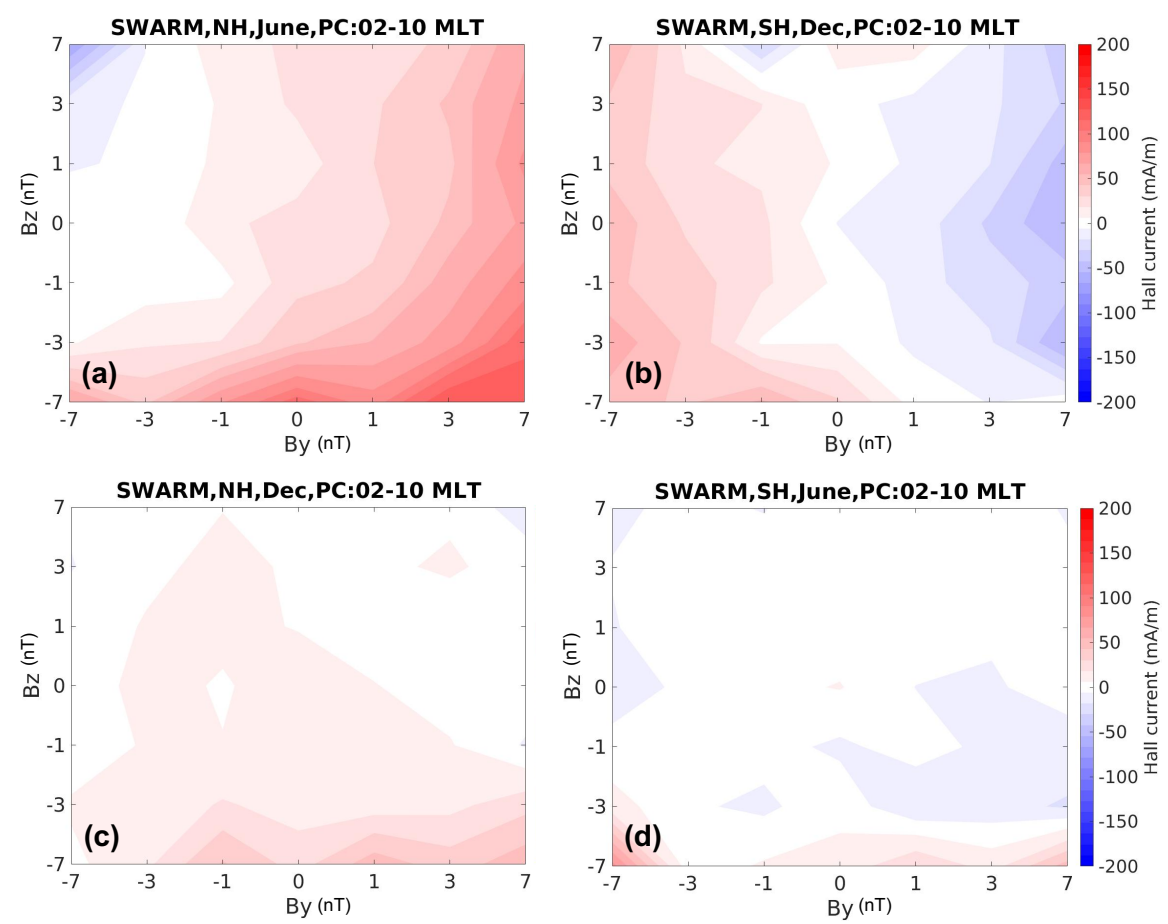

Figure S5. Same format as Figure S1 but for the dawnside polar cap.

\section{PC: 14-22 MLT}
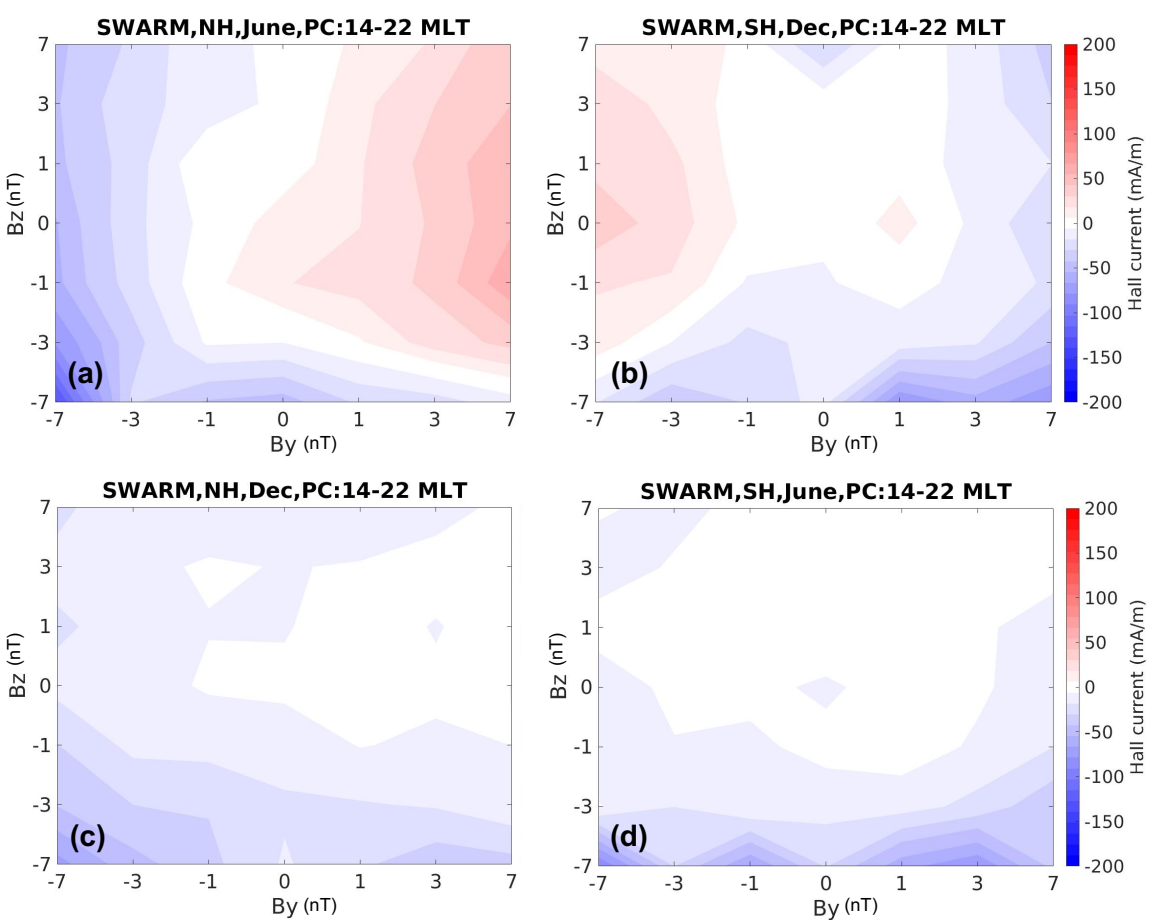

Figure S6. Same format as Figure S1 but for the duskside polar cap. 